\title{
External carotid compression: a novel technique to improve cerebral perfusion during selective antegrade cerebral perfusion for aortic arch surgery
}

\section{La compression externe de la carotide: une technique innovante pour améliorer la perfusion cérébrale pendant une perfusion cérébrale antérograde sélective pour une chirurgie de la crosse aortique}

\author{
Hilary P. Grocott, MD · Emma Avery, MSc • Mike Moon, MD \\ Received: 20 April 2016/Revised: 13 June 2016/Accepted: 6 July 2016/Published online: 18 July 2016 \\ (C) Canadian Anesthesiologists' Society 2016
}

\begin{abstract}
Purpose Selective antegrade cerebral perfusion (SACP) involving cannulation of either the axillary or innominate artery is a commonly used technique for maintaining cerebral blood flow $(C B F)$ during the use ofhypothermic cardiac arrest (HCA) for operations on the aortic arch. Nevertheless, asymmetrical CBF with hypoperfusion of the left cerebral hemisphere is a common occurrence during $S A C P$. The purpose of this report is to describe an adjunctive maneuver to improve left hemispheric $C B F$ during SACP by applying extrinsic compression to the left carotid artery.

Clinical features A 77-yr-old male patient with a history of aortic valve replacement presented for emergent surgical repair of an acute type A aortic dissection of a previously known ascending aortic aneurysm. His intraoperative course included cannulation of the right axillary artery, which was
\end{abstract}

Electronic supplementary material The online version of this article (doi:10.1007/s12630-016-0699-6) contains supplementary material, which is available to authorized users.

H. P. Grocott, MD ( $\square)$

Departments of Anesthesia \& Perioperative Medicine and

Surgery, University of Manitoba, CR3008 - 369 Tache Avenue,

Winnipeg, MB R2H 2A6, Canada

e-mail: hgrocott@sbgh.mb.ca

E. Avery MSc

Department of Anesthesia and Perioperative Medicine,

University of Manitoba, Winnipeg, MB, Canada

M. Moon, MD

Department of Surgery, University of Alberta, Edmonton, AB,

Canada used as the aortic inflow during cardiopulmonary bypass and also allowed for subsequent SACP during HCA. After the onset of HCA, the innominate artery was clamped at its origin to allow for SACP. Shortly thereafter, however, the left-sided cerebral oxygen saturation $\left(\mathrm{SrO}_{2}\right)$ began to decrease. Augmenting the $\mathrm{PaO}_{2}, \mathrm{PaCO}_{2}$ and both $\mathrm{SACP}$ pressure and flow failed to increase left hemispheric $\mathrm{SrO}_{2}$. Following the use of ultrasound guidance to confirm the absence of atherosclerotic disease in the carotid artery, external pressure was applied partially compressing the artery. With the carotid compression, the left cerebral saturation abruptly increased, suggesting pressurization of the left cerebral hemispheric circulation and augmentation of CBF.

Conclusions Direct ultrasound visualization and cautious partial compression of the left carotid artery may address asymmetrical CBF that occurs with SACP during HCA for aortic arch surgery. This strategy may lead to improved symmetry of $C B F$ and corresponding cerebral oximetry measurements during aortic arch surgery.

\section{Résumé}

Objectif La perfusion cérébrale antérograde sélective réalisée via la canulation de l'artère axillaire ou du tronc artériel brachiocéphalique est une technique répandue pour maintenir la circulation sanguine cérébrale pendant un arrêt circulatoire hypothermique pour les opérations de la crosse aortique. Toutefois, on observe fréquemment une circulation sanguine cérébrale asymétrique accompagnée d'une hypoperfusion de l'hémisphère cérébrale gauche pendant la perfusion cérébrale antérograde sélective. L'objectif de ce compte rendu est de décrire une manœuvre d'appoint destinée à améliorer la circulation sanguine cérébrale pendant la 
perfusion cérébrale antérograde sélective en appliquant une compression extrinsèque à l'artère carotide gauche.

Éléments cliniques Un homme de 77 ans avec des antécédents de remplacement valvulaire aortique s'est présenté pour une réparation chirurgicale urgente d'une dissection aortique aiguë de type Ad'un anévrisme de l'aorte ascendante connu. Son parcours peropératoire a inclus la canulation de l'artère axillaire droite, qui a été utilisée comme canule artérielle pendant la circulation extracorporelle et a également permis la perfusion cérébrale antérograde sélective subséquente pendant l'arrêt circulatoire hypothermique. Après l'amorce de l'arrêt circulatoire hypothermique, le tronc artériel brachiocéphalique a été clampé à sa base afin de permettre la perfusion cérébrale antérograde sélective. Peu après toutefois, la saturation en oxygène cérébral $\left(\mathrm{SrO}_{2}\right)$ gauche a commencé à baisser. L'augmentation de la $\mathrm{PaO}_{2}$, de la $\mathrm{PaCO}_{2}$ et de la pression et du débit de perfusion cérébrale antérograde sélective n'a pas réussi à augmenter la $\mathrm{SrO}_{2}$ dans l'hémisphère gauche. Après avoir utilisé l'échographie pour confirmer l'absence d'athérosclérose dans l'artère carotide, une pression externe a été appliquée en comprimant partiellement l'artère. En comprimant la carotide, la saturation cérébrale gauche a subitement augmenté, suggérant une pressurisation de la circulation hémisphérique cérébrale gauche et une augmentation de la circulation sanguine cérébrale.

Conclusion Une visualisation directe par échographie et une compression partielle prudente de l'artère carotide gauche pourraient régler le problème de circulation sanguine cérébrale asymétrique qui survient en cas de perfusion cérébrale antérograde sélective pendant l'arrêt circulatoire hypothermique pour la chirurgie de la crosse aortique. Cette stratégie pourrait améliorer la symétrie de la circulation sanguine cérébrale et les mesures de l'oxymétrie cérébrale correspondantes pendant les chirurgies de la crosse aortique.

Selective antegrade cerebral perfusion (SACP) is a technique commonly used to maintain cerebral blood flow $(\mathrm{CBF})$ during the use of hypothermic circulatory arrest (HCA) for operations on the aortic arch. ${ }^{1}$ The technique involves cannulation of either the right axillary artery or the innominate artery with concomitant clamping of the innominate artery near its origin at the aortic arch to allow for continual blood flow into the right carotid artery. This right carotid flow provides CBF to the right cerebral hemisphere and subsequently to the left cerebral circulation via collaterals in the Circle of Willis. Nevertheless, even with an intact Circle of Willis (which can be incomplete in $15 \%$ of the population), ${ }^{2}$ asymmetric CBF is a common occurrence during HCA when SACP is used. ${ }^{3}$ Such an occurrence is due to the relatively low resistance pathway away from the left hemisphere via the left carotid artery, which often remains open to the aortic arch in the surgical field and induces a carotid "steal" phenomenon. Regional cerebral oxygen saturation $\left(\mathrm{SrO}_{2}\right)$, measured via nearinfrared spectroscopy-derived cerebral oximetry, can be used as an indirect monitor of CBF and uncover significant asymmetry in $\mathrm{CBF}$ with decreases in left hemispheric perfusion during SACP.

A number of strategies have been used to ameliorate the decreases in left-sided CBF that are frequently seen during
A

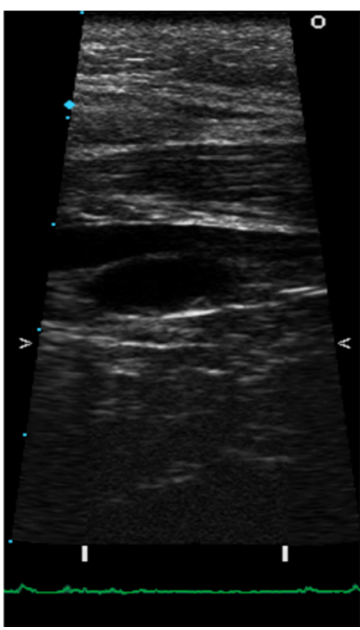

B

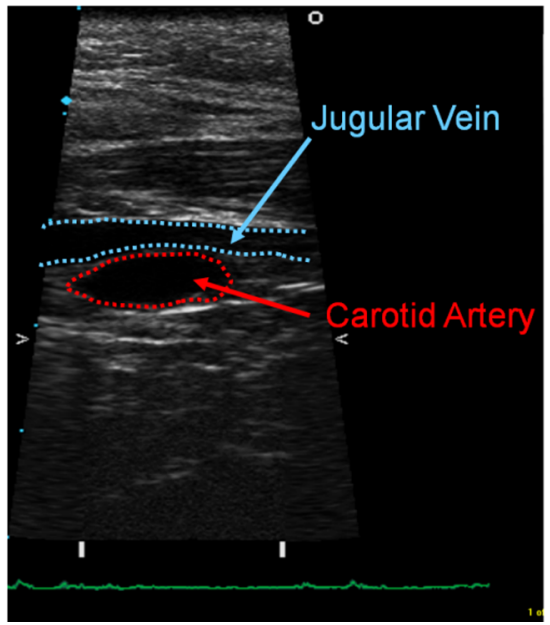

C

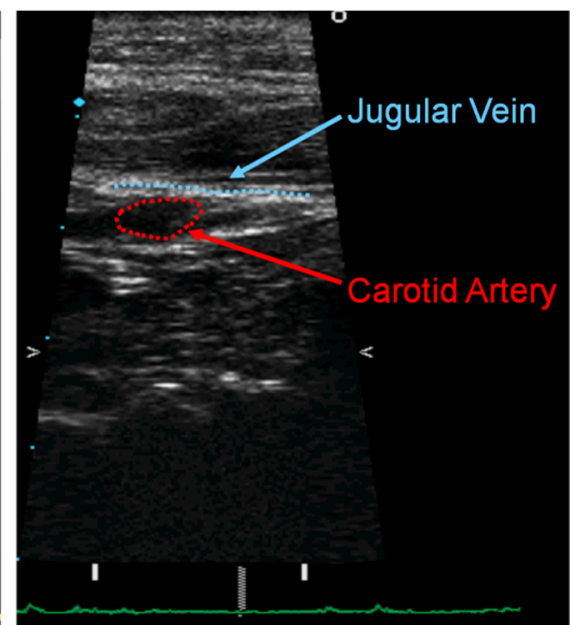

Fig. 1 Image A represents the ultrasound image of the left carotid artery (CA) during aortic surgery where the internal jugular vein (JV) can be seen deep to the CA. The CA is free of any calcific atherosclerosis. Image $\mathrm{B}$ represents the $\mathrm{CA}$ and $\mathrm{JV}$ schematic superimposed over the original image. Image $\mathrm{C}$ represents the ultrasound image of the left carotid artery (CA) when the anesthesiologist applied external neck pressure. The JV is completely compressed, but the CA is only partially compressed 
Fig. 2 Cerebral oximetry measurements of bilateral cerebral oxygen saturation during a case of aortic arch reconstruction employing hypothermic circulatory arrest (HCA) and selective antegrade cerebral perfusion (SACP). The open arrow indicates the reduction in cerebral saturation involving the left frontal lobe shortly after the onset of SACP and HCA. The closed arrows indicate repeated application of left carotid artery compression using the ultrasound probe at the level of the cricoid cartilage

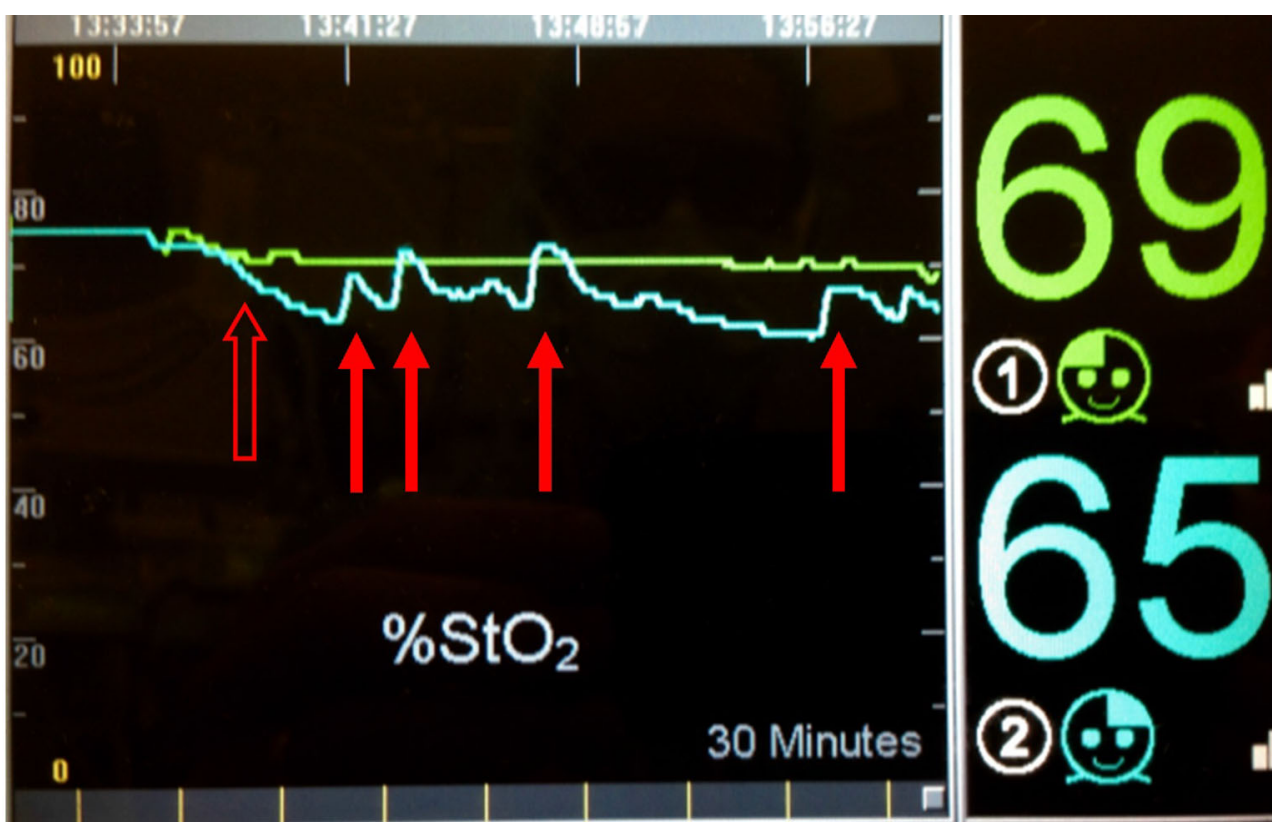

SACP. Such approaches include concomitant direct cannulation of the left carotid artery from within the aortic arch with a balloon-tipped cannula, ${ }^{4}$ as well as direct external clamping of the left carotid artery near its origin from the aortic arch; both techniques are not without limitations.

In this case report, we present an alternative maneuver to avoid the abovementioned limitations. This option might be considered for the patient undergoing complex aortic arch surgery involving HCA when cerebral saturation indicates a reduction in the contralateral $\mathrm{CBF}$ during SACP.

\section{Clinical details}

A 77-yr-old male with a history of aortic valve replacement presented for surgical repair of an acute type A aortic dissection of a previously known ascending aortic aneurysm. The dissection entry point was in the distal ascending aorta and extended into the distal descending thoracic aorta. The carotid and vertebral arteries were free of any intimal flap extensions. The cerebral vasculature (i.e., Circle of Willis) was not imaged preoperatively. The patient provided written consent for this case report.

His intraoperative course included cannulation for cardiopulmonary bypass (CPB). This involved a $10-\mathrm{mm}$ Dacron graft being anastomosed to the right axillary artery to be used for the aortic inflow during CPB as well as to allow subsequent SACP during HCA. In addition to routine intraoperative monitoring, ${ }^{5}$ cerebral oximetry sensors (FORE-SIGHT $^{\mathrm{TM}}$; CAS Medical Systems Inc, Branford,
CT, USA) were placed bilaterally over the patient's frontal lobes. During the cooling phase prior to HCA, bilateral symmetrical $\mathrm{SrO}_{2}$ was noted. Hypothermic circulatory arrest was instituted when the nasopharyngeal temperature reached $25^{\circ} \mathrm{C}$. This was followed by clamping of the innominate artery, and SACP was then implemented via the axillary artery graft with flows of $0.75-1.2 \mathrm{~L} \cdot \mathrm{min}^{-1}$ Although bilateral symmetrical cerebral saturation was observed during the initial period (i.e., 1-2 min) of SACP, shortly thereafter, the left-sided cerebral saturation began to decrease disproportionately (i.e., $>10 \%$ ) from the right side. Augmenting the $\mathrm{PaO}_{2}, \mathrm{PaCO}_{2}$ and both pressure and flow of SACP failed to increase left hemispheric cerebral saturation. The duration of HCA was $21 \mathrm{~min}$.

This patient previously underwent a median sternotomy and had significant adhesions present in the upper mediastinum. Consequently, there was limited access to the left carotid artery at the level of the aortic arch, so clamping it was not an option. The access to the left carotid artery was further compromised by a periaortic hematoma from the aortic aneurysm and associated dissection. Furthermore, direct cannulation via the carotid orifice was not considered prudent due to concerns regarding the potential for age-related atheromatous disease in the proximal carotid artery (despite no obvious findings on computed tomography or transesophageal echocardiography).

Surface ultrasound (Diamond Select iE33 Ultrasound system; Philips, Bothwell, WA, USA; L15-7io Philips Ultrasound Probe; Bothwell, WA, USA) guidance was used to identify the carotid artery at the level of the cricoid cartilage, and after ruling out any significant atheroma, 
external pressure was applied with the ultrasound probe to partially compress the left carotid artery (Fig. 1-C; see also the video in the Electronic Supplementary Material). Almost immediately after commencing the extrinsic compression, the left cerebral saturation abruptly increased, consistent with pressurization of the cerebral circulation in the left hemisphere and augmentation of left CBF (Fig. 2). This technique was repeated several times during the 21-min period of HCA in order to confirm the ability of the external carotid compression to augment CBF. Continuous compression was not used, and the intermittent period of compression served simply as a "proof in principle" that this technique could be effective in reversing the saturation event. No specific Doppler imaging of the carotid was undertaken. The remainder of the hemiarch repair of the aorta proceeded uneventfully, and repeat ultrasound imaging of the left carotid at the end of the case did not reveal any obvious pathology resulting from the compression.

The patient made a relatively uncomplicated recovery, apart from some transient delirium, and he had no other overt symptoms of other generalized or focal neurologic injury. He was discharged home on the tenth postoperative day and continues to remain in good health.

\section{Discussion}

Asymmetrical CBF is frequently seen during the conduct of SACP during HCA for aortic arch surgery. This case report illustrates the utilization of a novel technique to reverse this potentially injurious event by employing direct ultrasound visualization of the left carotid artery along with ultrasound-guided partial compression of the artery. This technique may lead to increased symmetry of CBF and corresponding improved cerebral oximetry during aortic arch surgery. The degree of asymmetrical desaturation deemed to be significant is not fully known, and as several different thresholds have been used, ${ }^{6}$ we arbitrarily chose a $10 \%$ reduction from baseline as the point to initiate our intervention.

Several other approaches have been used to optimize CBF during HCA and SACP and to ameliorate the decrease that is frequently seen in the left-sided cerebral circulation. $^{7}$ One such strategy includes concomitant direct cannulation of the left carotid artery from within the aortic arch with a balloon-tipped cannula. ${ }^{4}$ In addition, direct clamping of the left carotid artery near its origin from the aortic arch has also been advocated. ${ }^{8}$ This technique has the added benefit of reducing the volume of blood flooding the surgical field caused by retrograde flow from collateral vessels in the Circle of Willis via the right-sided circulation that exits at the carotid orifice into the arch. Nevertheless, both of these maneuvers to reduce this carotid steal increase the risk of direct trauma to the carotid artery as well as the generation of embolic debris from what is frequently an atheromatous vessel. In addition, both approaches require additional surgical time and subsequent distraction from the primary operation.

In contrast, the adjunctive maneuver suggested in this report offers several advantages. It can be performed without distracting the surgical team from the primary aortic graft anastomosis to any additional surgical dissection of the carotid artery for direct clamping (thus avoiding any need for additional surgical time). Furthermore, it does not involve the potential for intraluminal trauma and possible generation of emboli from direct cannulation. Nevertheless, external carotid compression may not be without its own risks. Localized endothelial trauma to the carotid artery is a concern, particularly if significant atherosclerotic disease is present. Nevertheless, this possibility can most likely be minimized by using ultrasound visualization and confirming the absence of overt atherosclerosis disease. Importantly, total occlusion of the vessel is not required - only partial compression is needed to reduce the carotid steal phenomenon. It would likely be inadvisable to use this maneuver in the presence of significant carotid stenosis. The type of ultrasound probe to use for an optimal image of the carotid artery should be one with relatively high frequency $(5-7 \mathrm{~Hz})$ and short focus, similar to that used to image for central venous cannulation.

As this is the initial description of this technique, the duration and degree of carotid compression to use is not known, but it is likely a valuable point to investigate in future studies. Whether this manual external carotid compression is a safer technique than direct cannulation is not known and could also be the subject of further study. Indeed, one concern may be the potential for ipsilateral jugular vein occlusion, though cerebral venous drainage can usually be accommodated if the contralateral jugular vein is intact. Importantly, after the compression is completed and normal circulation has been restored, it is important to image the carotid artery in order to confirm the absence of injury from the compression.

In summary, this technique offers significant advantages and can likely be instituted in many patients undergoing SACP during HCA. Although no systematic study of this maneuver has been conducted, it could be considered for most SACP cases wherein the left $\mathrm{SrO}_{2}$ cannot be increased by conventional means.

\section{Competing interests None declared.}

Author contributions Hilary P. Grocott contributed to all aspects of this manuscript, including acquisition, analysis, and interpretation 
of the data and drafting of the article. Emma Avery contributed to drafting of the article. Michael Moon contributed to interpretation of the data and drafting of the article.

Editorial responsibility This submission was handled by Dr. Gregory L. Bryson, Deputy Editor-in-Chief, Canadian Journal of Anesthesia.

\section{References}

1. Tsai JY, Pan W, Lemaire SA, et al. Moderate hypothermia during aortic arch surgery is associated with reduced risk of early mortality. J Thorac Cardiovasc Surg 2013; 146: 662-7.

2. Iqbal $S$. A comprehensive study of the anatomical variations of the circle of willis in adult human brains. J Clin Diagn Res 2013; 7 : 2423-7.
3. Fischer $G W$, Lin HM, Krol M, et al. Noninvasive cerebral oxygenation may predict outcome in patients undergoing aortic arch surgery. J Thorac Cardiovasc Surg 2011; 141: 815-21.

4. Chan SK, Underwood MJ, Ho AM, et al. Cannula malposition during antegrade cerebral perfusion for aortic surgery: role of cerebral oximetry. Can J Anesth 2014; 61: 736-40.

5. Merchant $R$, Chartrand D, Dain S, et al. Guidelines to the practice of anesthesia-revised edition 2015. Can J Anesth 2015; 62: 54-67.

6. Deschamps A, Hall R, Grocott $H$, et al. Cerebral oximetry monitoring to maintain normal cerebral oxygen saturation during high-risk cardiac surgery: a randomized controlled feasibility trial. Anesthesiology 2016; 124: 826-36.

7. Fischer $G W$, Benni PB, Lin HM, et al. Mathematical model for describing cerebral oxygen desaturation in patients undergoing deep hypothermic circulatory arrest. Br J Anaesth 2010; 104: 5966.

8. Rylski B, Urbanski PP, Siepe $M$, et al. Operative techniques in patients with type A dissection complicated by cerebral malperfusion. Eur J Cardiothorac Surg 2014; 46: 156-66. 